\title{
A new species of genus Gilliesia Peters \& Edmunds from China (Ephemeroptera: Leptophlebiidae)
}

\author{
CHANG-FA ZHOU \\ Institute of Genetic Resources, College of Life Sciences, Nanjing Normal University, Nanjing 210097, P. R. \\ China \\ e-mail: cfzhou@eyou.com
}

\begin{abstract}
Gilliesia pulchra n. sp., the second known species of the genus Gilliesia Peters and Edmunds, is described from male and female imagos collected in Southwestern China. The new species represents a new generic record for this country and extends the known distribution of the genus east across the Himalayan Mountains.
\end{abstract}

Key words: Gilliesia, Leptophlebiidae, Ephemeroptera, China, Gilliesia pulchra new species

\section{Introduction}

The genus Gilliesia was established by Peters and Edmunds in 1970 based on a previously known species originally described in the genus Thraulus, Gilliesia hindustanica (Gillies, 1951). Published records include the type locality in Northern India (West Bengal, Darjeeling District, Mirik) and additional specimens from Assam (Arunachal Pradesh, formerly N.E. Frontier Agency) (Peters and Edmunds 1970). In 2000, a new species of this genus was collected from Jing-Fu-Shan mountain of Mainland China. It is described herein from imagos. The new species represents a new generic record for China.

\section{Gilliesia pulchra n. sp.}

Male imago (in alcohol): body length $7.5 \mathrm{~mm}$, fore leg $12.5 \mathrm{~mm}$, fore wing $8.0 \mathrm{~mm}$, hind wing $1.2 \mathrm{~mm}$. Compound eyes dark basally and gray apically; antennae pale, ocelli pale apically with basal reddish ring. Vertex of head and pronotum pale. Mesonotum pale, with 2 pairs of brown round dots, one pair located near anterior margin, the other two near pos- 
terior margin. Wing base dark. Metanotum with yellowish-brown posterior margin. Forefemora washed with indistinct gray to brownish pigments in basal half, brown band in posterior $3^{\text {rd }}$ and apices brown; tibiae pale, brown at apices; tarsi pale. Mid- and hindlegs pale, with femora pale yellow. Ratio of forefemora: tibiae: tarsi $=1.0: 1.5: 1.8$, that of midand hindlegs $=1.0: 1.5: 0.6$; arrangement of foretarsal segments from longest to shortest 2, $3,4,5,1$. Forewing transparent, cross veins yellowish-brown, those in C-Sc, Sc- $R_{1}$ and $R_{1-}$ Rs cells surrounded by dark reddish-brown clouds forming markings as shown in Fig. 1; $\mathrm{MA}$ fork asymmetrical, fork a little basal to middle of wing; $\mathrm{MP}_{2}$ independent of vein $\mathrm{MP}_{1}$ at base; two long intercalaries between $\mathrm{CuA}$ and $\mathrm{CuP}$. Hind wing very small with distinct acute costal projection past middle of wing (Fig. 2). Abdominal terga 1-8 translucent white, terga 9-10 opaque, cream; tergum 9 with one pair of median longitudinal brown stripes; all terga with brown posterior margins. Caudal filaments pale. Genitalia (Fig. 3-4): basal segment of forceps much longer than apical segments, $2^{\text {nd }}$ segment distinctly broadened, apical segment smallest. Styliger plate with deep U-shaped median cleft. Penes tubelike, apical portion of each lobe bent laterally and then ventrally, apex of each penis lobe tapered.

Female imago (in alcohol): body length $8.5 \mathrm{~mm}$, fore wing $10.0 \mathrm{~mm}$, hind wing 1.5 $\mathrm{mm}$. Body color darker than male. Vertex of head brown. Pronotum pale, with a transverse dark brown stripe on anterior margin and a pair of additional "X"-shaped submedian dark marks. Meso- and metanotum yellowish-brown, lateral and ventral parts of body pale. Forefemora yellowish-brown with brown apices, washed with irregular and unclear gray pigments in basal half, apices and subapices brown; tibiae and tarsi pale with apices of tibiae reddish-brown. Mid- and hindlegs pale, femora pale yellow. Ratio of femora: tibiae: tarsi of forelegs $=1.0: 1.5: 0.9$, of mid- and hindlegs $=1.0: 1.25: 0.5$. Abdomen yellowishbrown, terga 1-10 each with 2 pairs of longitudinal brown stripes, outer stripes broader than middle pair and incurved, meeting posteriorly (Fig. 5), posterior margins dark brown. Color pattern of wing similar to that of male, but crossveins darker, surrounded by reddishbrown pigments, more distinct than those of male. Sternum 7 slightly expanded posteromedially. Apex of sternum 9 with deep median cleft (Fig. 6).

Larva: unknown.

Diagnosis: In the males, Gilliesia pulchra n. sp. can be distinguished from G. hindustanica by the shape of the apex of the penis lobes: those of $G$. hindustanica are broad and those of G. pulchra n. sp. are tapered. Further, the tibiae of the forelegs are longer than femora and the tarsi are longer than the tibiae, but in G. hindustanica the tibiae are equal in length to the tarsi, which are about twice as long as the femora. Gilliesia pulchra n. sp. also lacks the brown median band on the forefemora and the apical femoral bands on the middle and hind legs of G. hindustanica (Gillies 1951). In the females, G. pulchra n. sp. has yellowish-brown abdominal terga with distinct markings (Fig. 5) while G. hindustanica has a dark orange brown abdomen with pitch brown posterior margin on terga 1-8 (Gillies 1951). 


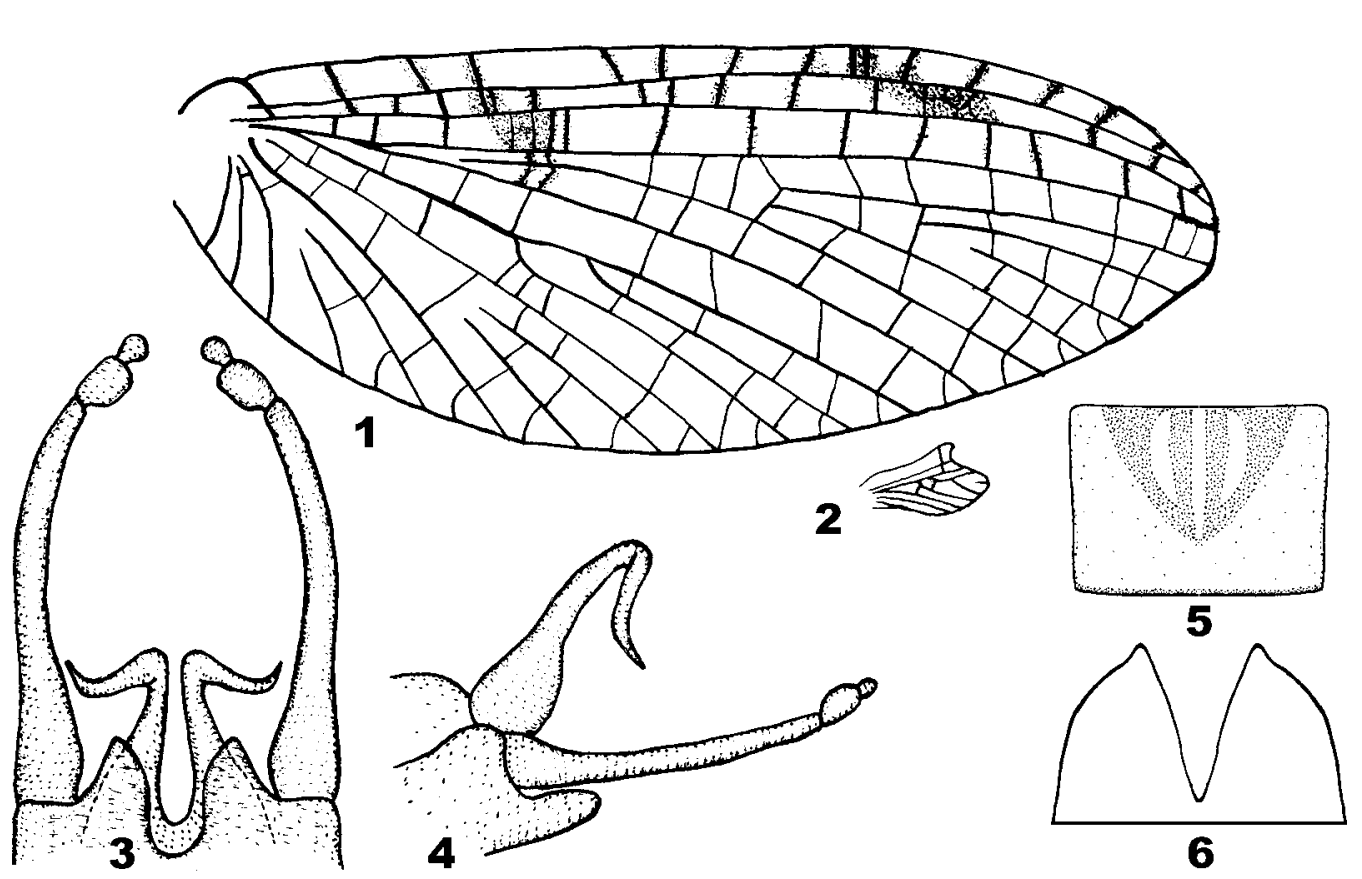

FIGURES 1-6, Gilliesia pulchra n. sp., imagos. Fig. 1-4, male: 1, forewing; 2, hind wing; 3, genitalia (ventral view); 4, genitalia (lateral view). Fig. 5-6, female: 5, color pattern of tergum 2; 6, apex of sternum 9 .

Etymology: The epithet of new species from pulcher (L., meaning beautiful), referring to the distinct and beautiful color pattern of the wings.

Material examined: Holotype male imago: P.R. CHINA: Chongqing municipality, Huang-Cao-Ping, Jing-Fu-Shan mountain, $29.00^{\circ} \mathrm{N}, 107.10^{\circ} \mathrm{E}$, ca. $1,200 \mathrm{~m}$ alt., 3-IX-2000, leg. LI Chuang-Ren \& ZHOU Chang-Fa. Paratypes: 3 male, 1 female, 3 male subimagos, same data as the holotype; 2 male and 1 female subimagos, Guizhou Province, Nan-Zhu forestry center, Chi-Shui City, $28.34^{\circ} \mathrm{N}, 105.42^{\circ} \mathrm{E}, 9-\mathrm{VI}-1995$, leg. SUN Chang-Hai \& WANG Bei-Xing. All types deposited in Nanjing Normal University, Nanjing, China.

Collection information: The holotype and paratypes from Jing-Fu-Shan mountain were collected in a bamboo forest by sweeping vegetation during the day. The forest is beside a small stream (width 1-2 m, water current less $1 \mathrm{~m} / \mathrm{s}$, depth less than $30 \mathrm{~mm}$ ), with a substrate of small stone and leaves.

Discussion: Previously, Gilliesia was known from northern India (Gillies 1951, Peters \& Edmunds 1970). The discovery of this genus in mainland China shows that the genus Gilliesia has much broader distribution than previously known. and extends to the east of the Himalaya Mountains. 
I would like to thank Dr. Li Chuan-Ren (Hubei Agricultural College, China), Sun ChangHai and Wang Bei-Xing (Nanjing Agricultural University, China) for their help in field collection and providing some specimens and Mrs. J. Peters (Florida A\&M University, USA) for examination of specimens from northern India and review of the manuscript. I also thank the journal reviewers for their comments. This work was supported by a postdoctoral fellowship to C.-F. Zhou by Nanjing Normal University and the National Natural and Science Foundation of China (Grant No. 30300037).

\section{References}

Gillies, M.T. (1951) Further notes on Ephemeroptera from India and South East Asia. Proceedings of the Royal Society of London (B), 20, 121-130.

Peters, W.L, \& Edmunds, G.F., Jr. (1970) Revision of the generic classification of the Eastern Hemisphere Leptophlebiidae (Ephemeroptera). Pacific Insects, 12, 157-240. 